\title{
Quantum computational calculations of a series of tetrathiafulvalene derivatives linked to N-methylthiocarbamoyl group
}

\author{
Tahar Abbaz ${ }^{1 *}$, Amel Bendjeddou ${ }^{1}$ and Didier Villemin ${ }^{2}$ \\ ${ }^{1}$ Laboratory of Aquatic and Terrestrial Ecosystems, Org. and Bioorg. Chem. Group, University of Mohamed-Cherif \\ Messaadia, Souk Ahras, 41000, Algeria. \\ ${ }^{2}$ Laboratory of Molecular and Thio-Organic Chemistry, UMR CNRS 6507, INC3M, FR 3038, Labex EMC3, ensicaen and \\ University of Caen, Caen 14050, France.
}

Publication history: Received 18 April 2018; revised on 05 May 2018; accepted on 15 May 2018

https://doi.org/10.30574/gscbps.2018.3.2.0031

\begin{abstract}
We investigate in this study, the quantum chemical computations of a series of tetrathiafulvalene derivatives linked to N-methylthiocarbamoyl group 1-4 using the DFT/B3LYP method with 6-31G (d,p) basis set. The optimized structures and geometrical parameters were determined by the same method cited above. In addition, a molecular electrostatic potential map (MEP) has been analyzed for predicting the reactive sites. The calculated HOMO and LUMO energies showed that charge transfer occurs within the molecule. The chemical reactivity parameters (chemical hardness and softness, electronegativity, chemical potential and electrophilicity index) were discussed clearly. To find out more reactive sites of the title molecules, condensed Fukui functions have been also calculated. Stability of the compounds arising from hyper-conjugative interaction and charge delocalization has been analyzed using Natural bond orbital (NBO) analysis. NLO properties related to polarizability and hyperpolarizability are also discussed to predict the applications of title compounds.
\end{abstract}

Keywords: Tetrathiafulvalenes; Density functional theory; Computational chemistry; Quantum chemical calculations

\section{Introduction}

Many efforts have been devoted in recent years to the development of new systems containing two or more tetrathiafulvalene (TTF) units [1-3]. Tetrathiafulvalene (TTF) and its derivatives have been extensively studied due to their versatile behaviors, such as reversible redox properties and strong electron donating capabilities for preparing charge-transfer (CT) salts [4], D-A systems and other fields [5-7]. Also, they are widely employed as components for both inter- and intramolecular charge transfer materials [8].Owing to their highly conjugated frame-work, they should fulfil some criteria necessary to reveal large third-order nonlinear optical susceptibilities.

Density functional theory (DFT) methods have been used to correlate reactivity with molecular properties including energy, charge, and polarizability [9-11]. Correlations can be made with the electron density as the central quantity for characterization of molecular properties [12].

In this context we are studying a theoretical investigation of a series of tetrathiafulvalene derivatives linked to $N$ methylthiocarbamoyl group 1-4 described in literature [13] by means of Gaussian 09W program within DFT/B3LYP method and 6-31G $(\mathrm{d}, \mathrm{p})$ basis set. We carried the optimized geometric parameters, molecular electrostatic potential (MESP) surface and contour map, quantum chemical descriptors (electronegativity, chemical potential, global softness

\footnotetext{
${ }^{*}$ Corresponding author

E-mail address: tahar.abbaz@ univ-soukahras.dz
}

Copyright (C) 2018 Author(s) retain the copyright of this article. This article is published under the terms of the Creative Commons Attribution Liscense 4.0. 
and electrophilicity index) and local density functional descriptors such as Fukui function. The Frontier molecular orbitals (FMOs) analysis was reported to study the molecular reactivity and stability of the molecules. The natural bond orbital (NBO) analysis was also carried out to understand the NLO activity of the title molecules.

\section{Material and methods}

The density functional theory DFT/B3LYP with the 6-31 G (d, p) as basis set was adopted to calculate the properties of (TTFs)- $N$-methylthiocarbamoyl 1-4 in the present work. The entire calculations were performed using Gaussian 09W program package [14].

\section{Results and discussion}

\subsection{Molecular geometry}

The optimized molecular structures of title molecules obtainedfrom Gauss view is shown in Figure 1. The optimization geometricalparameters of (TTFs)- $N$-methylthiocarbamoyl 1-4 obtained by B3LYP method with6-31G(d,p) as basis set are listed in Tables 1-4.

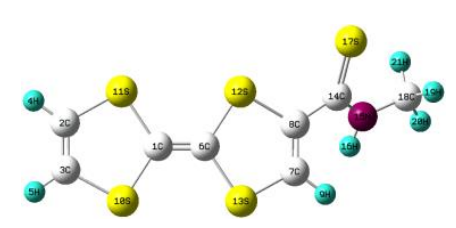

Compound 1
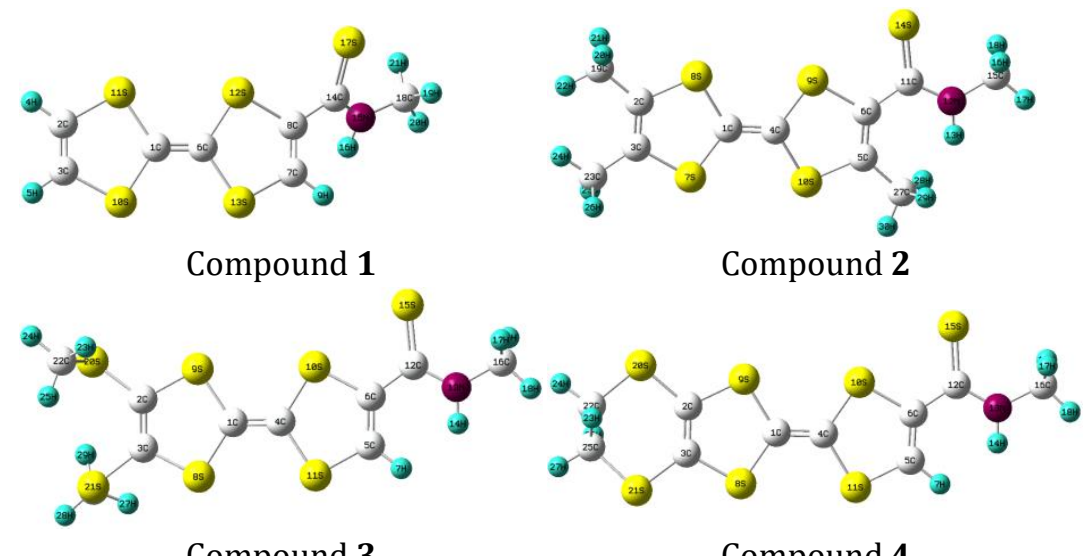

Compound 4

Figure 1 Optimized molecular structure of (TTFs)- $N$-methylthiocarbamoyl 1-4

Table 1 Optimized geometric parameters of compound 1

\begin{tabular}{|c|c|c|c|c|c|}
\hline \multicolumn{2}{|c|}{ Bond Length $(\AA)$} & \multicolumn{2}{|c|}{ Bond Angles $\left({ }^{\circ}\right)$} & \multicolumn{2}{|c|}{ Dihedral Angles ( $\left(^{\circ}\right)$} \\
\hline$R(1,6)$ & 1.316 & $\mathrm{~A}(6,1,10)$ & 123.554 & $\mathrm{D}(10,1,6,12)$ & 179.300 \\
\hline $\mathrm{R}(2,4)$ & 1.068 & $\mathrm{~A}(10,1,11)$ & 113.149 & $\mathrm{D}(11,1,6,13)$ & 179.779 \\
\hline$R(7,9)$ & 1.069 & $\mathrm{~A}(3,2,11)$ & 118.763 & $\mathrm{D}(6,1,10,3)$ & 177.629 \\
\hline $\mathrm{R}(8,7)$ & 1.323 & $\mathrm{~A}(4,2,11)$ & 116.170 & $\mathrm{D}(6,1,11,2)$ & 177.635 \\
\hline $\mathrm{R}(2,11)$ & 1.811 & $A(2,3,5)$ & 125.165 & $\mathrm{D}(4,2,3,10)$ & 179.741 \\
\hline $\mathrm{R}(6,13)$ & 1.830 & $\mathrm{~A}(8,7,13)$ & 119.669 & $D(11,2,3,5)$ & 179.756 \\
\hline $\mathrm{R}(7,13)$ & 1.799 & $\mathrm{~A}(9,7,13)$ & 115.767 & $\mathrm{D}(4,2,11,1)$ & 178.661 \\
\hline $\mathrm{R}(8,12)$ & 1.824 & $\mathrm{~A}(7,8,12)$ & 117.414 & $D(5,3,10,1)$ & 178.661 \\
\hline $\mathrm{R}(8,14)$ & 1.476 & $\mathrm{~A}(7,8,14)$ & 124.177 & $\mathrm{D}(1,6,12,8)$ & 170.165 \\
\hline$R(14,15)$ & 1.328 & $\mathrm{~A}(12,8,14)$ & 118.349 & $\mathrm{D}(1,6,13,7)$ & 170.668 \\
\hline$R(15,18)$ & 1.457 & $\mathrm{~A}(8,14,17)$ & 121.691 & $\mathrm{D}(9,7,8,12)$ & 175.362 \\
\hline $\mathrm{R}(17,14)$ & 1.711 & $\mathrm{~A}(15,14,17)$ & 123.496 & $\mathrm{D}(13,7,8,14)$ & 178.453 \\
\hline$R(19,18)$ & 1.079 & $\mathrm{~A}(14,15,16)$ & 118.301 & $\mathrm{D}(9,7,13,6)$ & 177.559 \\
\hline $\mathrm{R}(18,21)$ & 1.080 & $\mathrm{~A}(15,18,19)$ & 110.478 & $D(14,8,12,6)$ & 175.326 \\
\hline$R(15,16)$ & 0.994 & $\mathrm{~A}(14,15,18)$ & 124.319 & $\mathrm{D}(7,8,14,17)$ & 139.941 \\
\hline
\end{tabular}


Table 2 Optimized geometric parameters of compound 2

\begin{tabular}{lcllll}
\hline \multicolumn{2}{l}{ Bond Length $(\AA)$} & \multicolumn{2}{l}{ Bond Angles $\mathbf{(}^{\circ}$ ) } & \multicolumn{2}{l}{ Dihedral Angles $\mathbf{(}^{\circ} \mathbf{)}$} \\
\hline $\mathrm{R}(1,4)$ & 1.348 & $\mathrm{~A}(4,1,7)$ & 123.812 & $\mathrm{D}(7,1,4,9)$ & 179.998 \\
$\mathrm{R}(1,7)$ & 1.781 & $\mathrm{~A}(4,1,8)$ & 122.910 & $\mathrm{D}(11,1,6,13)$ & 179.779 \\
$\mathrm{R}(1,8)$ & 1.780 & $\mathrm{~A}(7,1,8)$ & 113.277 & $\mathrm{D}(6,1,10,3)$ & 177.629 \\
$\mathrm{R}(4,9)$ & 1.787 & $\mathrm{~A}(3,2,8)$ & 117.358 & $\mathrm{D}(6,1,11,2)$ & 177.635 \\
$\mathrm{R}(6,9)$ & 1.789 & $\mathrm{~A}(3,2,19)$ & 127.814 & $\mathrm{D}(4,2,3,10)$ & 179.741 \\
$\mathrm{R}(2,19)$ & 1.503 & $\mathrm{~A}(8,2,19)$ & 114.827 & $\mathrm{D}(11,2,3,5)$ & 179.756 \\
$\mathrm{R}(6,11)$ & 1.477 & $\mathrm{~A}(2,3,7)$ & 115.767 & $\mathrm{D}(4,2,11,1)$ & 178.661 \\
$\mathrm{R}(5,27)$ & 1.511 & $\mathrm{~A}(2,3,23)$ & 127.989 & $\mathrm{D}(5,3,10,1)$ & 178.661 \\
$\mathrm{R}(11,12)$ & 1.352 & $\mathrm{~A}(7,3,23)$ & 114.902 & $\mathrm{D}(1,6,12,8)$ & 170.165 \\
$\mathrm{R}(12,13)$ & 1.004 & $\mathrm{~A}(1,4,9)$ & 123.482 & $\mathrm{D}(1,6,13,7)$ & 170.668 \\
$\mathrm{R}(12,15)$ & 1.453 & $\mathrm{~A}(1,4,10)$ & 122.778 & $\mathrm{D}(9,7,8,12)$ & 175.362 \\
$\mathrm{R}(15,17)$ & 1.092 & $\mathrm{~A}(9,4,10)$ & 113.739 & $\mathrm{D}(13,7,8,14)$ & 178.453 \\
$\mathrm{R}(23,26)$ & 1.096 & $\mathrm{~A}(6,5,10)$ & 117.399 & $\mathrm{D}(9,7,13,6)$ & 177.559 \\
$\mathrm{R}(22,19)$ & 1.091 & $\mathrm{~A}(6,5,27)$ & 129.274 & $\mathrm{D}(14,8,12,6)$ & 175.326 \\
$\mathrm{R}(27,28)$ & 1.096 & $\mathrm{~A}(10,5,27)$ & 113.321 & $\mathrm{D}(7,8,14,17)$ & 139.941 \\
\hline
\end{tabular}

Table 3 Optimized geometric parameters of compound 3

\begin{tabular}{llllll}
\hline \multicolumn{2}{l}{ Bond Length $(\AA)$} & \multicolumn{2}{l}{ Bond Angles $\left(^{\circ}\right)$} & \multicolumn{2}{l}{ Dihedral Angles ( $)$} \\
\hline $\mathrm{R}(1,6)$ & 1.316 & $\mathrm{~A}(6,1,10)$ & 123.554 & $\mathrm{D}(10,1,6,12)$ & 179.300 \\
$\mathrm{R}(2,4)$ & 1.068 & $\mathrm{~A}(10,1,11)$ & 113.149 & $\mathrm{D}(11,1,6,13)$ & 179.779 \\
$\mathrm{R}(7,9)$ & 1.069 & $\mathrm{~A}(3,2,11)$ & 118.763 & $\mathrm{D}(6,1,10,3)$ & 177.629 \\
$\mathrm{R}(8,7)$ & 1.323 & $\mathrm{~A}(4,2,11)$ & 116.170 & $\mathrm{D}(6,1,11,2)$ & 177.635 \\
$\mathrm{R}(2,11)$ & 1.811 & $\mathrm{~A}(2,3,5)$ & 125.165 & $\mathrm{D}(4,2,3,10)$ & 179.741 \\
$\mathrm{R}(6,13)$ & 1.830 & $\mathrm{~A}(8,7,13)$ & 119.669 & $\mathrm{D}(11,2,3,5)$ & 179.756 \\
$\mathrm{R}(7,13)$ & 1.799 & $\mathrm{~A}(9,7,13)$ & 115.767 & $\mathrm{D}(4,2,11,1)$ & 178.661 \\
$\mathrm{R}(8,12)$ & 1.824 & $\mathrm{~A}(7,8,12)$ & 117.414 & $\mathrm{D}(5,3,10,1)$ & 178.661 \\
$\mathrm{R}(8,14)$ & 1.476 & $\mathrm{~A}(7,8,14)$ & 124.177 & $\mathrm{D}(1,6,12,8)$ & 170.165 \\
$\mathrm{R}(14,15)$ & 1.328 & $\mathrm{~A}(12,8,14)$ & 118.349 & $\mathrm{D}(1,6,13,7)$ & 170.668 \\
$\mathrm{R}(15,18)$ & 1.457 & $\mathrm{~A}(8,14,17)$ & 121.691 & $\mathrm{D}(9,7,8,12)$ & 175.362 \\
$\mathrm{R}(17,14)$ & 1.711 & $\mathrm{~A}(15,14,17)$ & 123.496 & $\mathrm{D}(13,7,8,14)$ & 178.453 \\
$\mathrm{R}(19,18)$ & 1.079 & $\mathrm{~A}(14,15,16)$ & 118.301 & $\mathrm{D}(9,7,13,6)$ & 177.559 \\
$\mathrm{R}(18,21)$ & 1.080 & $\mathrm{~A}(15,18,19)$ & 110.478 & $\mathrm{D}(14,8,12,6)$ & 175.326 \\
$\mathrm{R}(15,16)$ & 0.994 & $\mathrm{~A}(14,15,18)$ & 124.319 & $\mathrm{D}(7,8,14,17)$ & 139.941 \\
\hline
\end{tabular}


Table 4 Optimized geometric parameters of compound 4

\begin{tabular}{lrllll}
\hline \multicolumn{2}{l}{ Bond Length (̊̊) } & \multicolumn{2}{l}{ Bond Angles $\left(^{\circ}\right)$} & \multicolumn{2}{l}{ Dihedral Angles ( $)$} \\
\hline $\mathrm{R}(1,6)$ & 1.316 & $\mathrm{~A}(6,1,10)$ & 123.554 & $\mathrm{D}(10,1,6,12)$ & 179.300 \\
$\mathrm{R}(2,4)$ & 1.068 & $\mathrm{~A}(10,1,11)$ & 113.149 & $\mathrm{D}(11,1,6,13)$ & 179.779 \\
$\mathrm{R}(7,9)$ & 1.069 & $\mathrm{~A}(3,2,11)$ & 118.763 & $\mathrm{D}(6,1,10,3)$ & 177.629 \\
$\mathrm{R}(8,7)$ & 1.323 & $\mathrm{~A}(4,2,11)$ & 116.170 & $\mathrm{D}(6,1,11,2)$ & 177.635 \\
$\mathrm{R}(2,11)$ & 1.811 & $\mathrm{~A}(2,3,5)$ & 125.165 & $\mathrm{D}(4,2,3,10)$ & 179.741 \\
$\mathrm{R}(6,13)$ & 1.830 & $\mathrm{~A}(8,7,13)$ & 119.669 & $\mathrm{D}(11,2,3,5)$ & 179.756 \\
$\mathrm{R}(7,13)$ & 1.799 & $\mathrm{~A}(9,7,13)$ & 115.767 & $\mathrm{D}(4,2,11,1)$ & 178.661 \\
$\mathrm{R}(8,12)$ & 1.824 & $\mathrm{~A}(7,8,12)$ & 117.414 & $\mathrm{D}(5,3,10,1)$ & 178.661 \\
$\mathrm{R}(8,14)$ & 1.476 & $\mathrm{~A}(7,8,14)$ & 124.177 & $\mathrm{D}(1,6,12,8)$ & 170.165 \\
$\mathrm{R}(14,15)$ & 1.328 & $\mathrm{~A}(12,8,14)$ & 118.349 & $\mathrm{D}(1,6,13,7)$ & 170.668 \\
$\mathrm{R}(15,18)$ & 1.457 & $\mathrm{~A}(8,14,17)$ & 121.691 & $\mathrm{D}(9,7,8,12)$ & 175.362 \\
$\mathrm{R}(17,14)$ & 1.711 & $\mathrm{~A}(15,14,17)$ & 123.496 & $\mathrm{D}(13,7,8,14)$ & 178.453 \\
$\mathrm{R}(19,18)$ & 1.079 & $\mathrm{~A}(14,15,16)$ & 118.301 & $\mathrm{D}(9,7,13,6)$ & 177.559 \\
$\mathrm{R}(18,21)$ & 1.080 & $\mathrm{~A}(15,18,19)$ & 110.478 & $\mathrm{D}(14,8,12,6)$ & 175.326 \\
$\mathrm{R}(15,16)$ & 0.994 & $\mathrm{~A}(14,15,18)$ & 124.319 & $\mathrm{D}(7,8,14,17)$ & 139.941 \\
\hline
\end{tabular}

\subsection{Molecular electrostatic potential (MEP)}

Molecular electrostatic potential (MEP) at a point in space around a molecule gives information about the net electrostatic effect produced at that point by total charge distribution (electron + proton) of the molecule and correlates with dipole moments, electro-negativity, partial charges and chemical reactivity of the molecules. It provides a visual method to understand the relative polarity of the molecule [15-16].

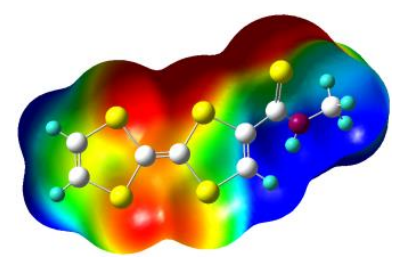

Compound 1

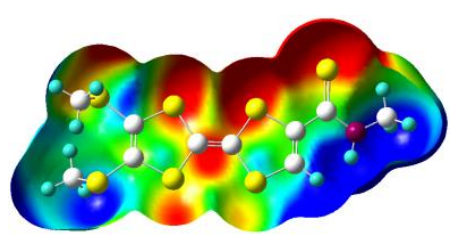

Compound 3

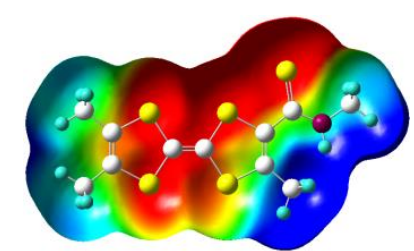

Compound 2

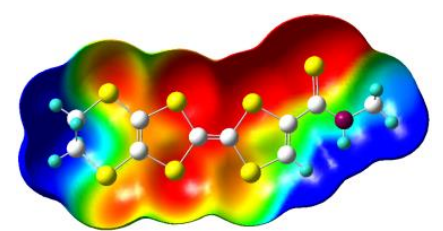

Compound 4

$-2.092 \mathrm{e}-2$ a.u

2.092e-2 a.u

Figure 2 Molecular electrostatic potential surface of (TTFs)- $N$-methylthiocarbamoyl 1-4

An electron density iso-surface mapped with electrostatic potential surface depicts the size, shape, charge density and site of chemical reactivity of the molecules. MEP shown in figure 2 calculated by DFT/B3LYP method with 6-31G (d, p) 
basis set is illustrates the charge distributions of the molecules three dimensionally. As it can be seen from the figure 2 , the different values of the electrostatic potential at the surface are represented by different colors; red represents regions of most electronegative electrostatic potential, blue represents regions of the most positive electrostatic potential and green represents regions of zero potential. Potential increases in the ordered, orange $<$ yellow $<$ green $<$ blue. Blue indicates the strongest attraction and red indicates the strongest repulsion. Regions of negative potential are usually associated with the lone pair of electronegative atoms.

As seen from the figure 2 that, in all molecules, the regions exhibiting the negative electrostatic potential are localized near TTF core and sulfur atom of $N$-methylthiocarbamoyl group while the regions presenting the positive potential are localized vicinity of the hydrogen atoms of alkyl and cycled groups.

\subsection{Frontier molecular orbitals (FMOs)}

In principle, there are several ways to calculate the excitation energies. The simplest one involves the difference between the highest occupied molecular orbital (HOMO) and the lowest unoccupied molecular orbital (LUMO) of a neutral system, and is a key parameter determining molecular properties. Both HOMO and LUMO are the main orbital taking part in chemical reaction. The HOMO energy characterizes the ability of electron giving, the LUMO characterizes the ability of electron accepting, and the gap between HOMO and LUMO characterizes the molecular chemical stability [17]. The energy gap between the HOMOs and LUMOs is a critical parameter in determining molecular electrical transport properties because it is a measure of electron conductivity [18].Surfaces for the frontier orbitals were drawn to understand the bonding scheme of present compound. It establishes correlation in various chemical and biochemical systems [19-20]. There are lot of applications available for the use of the highest occupied molecular orbital (HOMO) and the lowest unoccupied molecular orbital (LUMO) energy gap as a quantum chemical descriptor. The HOMO energies, the LUMO energies and the energy gap for(TTFs)- $N$-methylthiocarbamoyl1-4have been calculated using B3LYP level with6-31G(d, p) basis set. The pictorial representation of the HOMO and the LUMO for compound 3is shown in Figure 3.

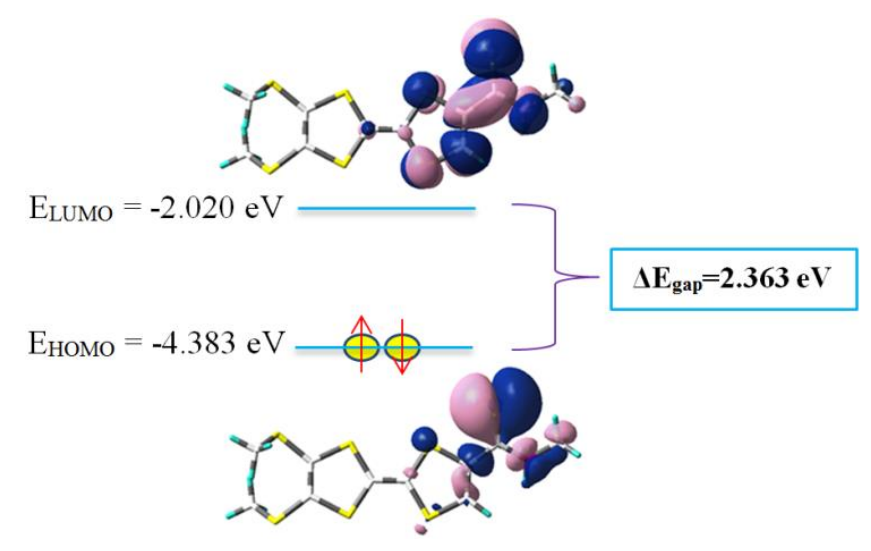

Figure 3 HOMO-LUMO Structure with the energy level diagram of compound 3

\subsection{Global reactivity descriptors}

The understanding of chemical reactivity and site selectivity of the molecular systems has been effectively handled by the conceptual density functional theory (DFT) [21]. Chemical potential, global hardness, global softness, electronegativity and electrophilicity are global reactivity descriptors, highly successful in predicting global chemical reactivity trends. The global parameters descriptors of (TTFs)- $N$-methylthiocarbamoyl 1-4 such as hardness ( $\eta$ ), $\operatorname{softness}(S)$, chemical potential $(\mu)$, electronegativity $(\chi)$ and electrophilicity index $(\omega)$ as well as local reactivity descriptors as the Fukui function and the philicity have been defined [22-26].Using Koopman's theorem for closedshell compounds, $\eta, \mu, \chi$ can be defined as:

$$
\begin{gathered}
\eta=(I-A) / 2 \\
\mu=-(I+A) / 2 \\
\chi=(I+A) / 2=-\mu \\
S=1 / \eta
\end{gathered}
$$




$$
I=-E_{H O M O} \text { and } A=-E_{L U M O}
$$

Where I and A are the ionization potential and electron affinity of the compounds, respectively. Parr et al. [23] have proposed electrophilicity index $(\omega)$ as a measure of energy lowering due to maximal electron flow between donor and acceptor. They defined electrophilicity index $(\omega)$ as follows:

$$
\omega=\mu^{2} / 2 \eta
$$

The electrophilicity is a descriptor of reactivity that allows a quantitative classification of the global electrophilic nature of a molecule within a relative scale. All the calculated values of HOMO-LUMO, energy gap, ionization potential, electron affinity, hardness, potential, softness and electrophilicity index are obtained by B3LYP/6-31G( $d, p)$ method and shown in Table 5.

Table 5 Quantum chemical descriptors of (TTFs)- $N$-methylthiocarbamoyl 1-4

\begin{tabular}{lllll}
\hline Parameters & Compound 1 & Compound 2 & Compound 3 & Compound 4 \\
\hline Еномо $(\mathrm{eV})$ & -7.569 & -4.396 & -4.383 & -5.805 \\
$\mathrm{E}_{\text {Luмо }}(\mathrm{eV})$ & -1.658 & -1.733 & -2.020 & -1.938 \\
$\Delta \mathrm{E}_{\text {gap }}(\mathrm{eV})$ & 9.226 & 2.663 & 2.363 & 3.867 \\
$\mathrm{I}(\mathrm{eV})$ & 7.569 & 4.396 & 4.383 & 5.805 \\
$\mathrm{~A}(\mathrm{eV})$ & 1.658 & 1.733 & 2.020 & 1.938 \\
$\mu(\mathrm{eV})$ & -2.956 & -3.064 & -3.202 & -3.872 \\
$\chi(\mathrm{eV})$ & 2.956 & 3.064 & 3.202 & 3.872 \\
$\eta(\mathrm{eV})$ & 4.613 & 1.331 & 1.181 & 1.934 \\
$\mathrm{~S}(\mathrm{eV})$ & 0.108 & 0.376 & 0.423 & 0.259 \\
$\omega(\mathrm{eV})$ & 0.947 & 3.526 & 4.339 & 3.876 \\
\hline
\end{tabular}

Еномо: Energy of highest occupied molecular orbital, $\mathrm{E}_{\text {Luмо: }}$ Energy oflowest unoccupied molecular orbital, $\Delta \mathrm{E}_{\text {gap }}$ : Energetic gap, I: Ionization potential, A: Electron affinity, $\mu$ : Chemical potential, $\chi$ : Electronegativity; $\eta$ : Hardness, S: Softness, $\omega$ : Electrophilicity index.

As presented in table 5, the compound which have the lowest energetic gap is the compound 3 ( $\Delta$ Egap $=2.363 \mathrm{eV}$ ). This lower gap allows it to be the softest molecule. The compound that have the highest energy gap is the compound 1 $(\Delta$ Egap $=9.226 \mathrm{eV})$. The compound that has the highest HOMO energy is the compound $3(\mathrm{EHOMO}=-4.383 \mathrm{eV})$. This higher energy allows it to be the best electron donor. The compound that has the lowest LUMO energy is the compound 3 (ELUMO $=-2.020 \mathrm{eV}$ ) which signifies that it can be the best electron acceptor. The two properties like I (potential ionization) and A (affinity) are so important, the determination of these two properties allow us to calculate the absolute electronegativity $(\chi)$ and the absolute hardness $(\eta)$. These two parameters are related to the one-electron orbital energies of the HOMO and LUMO respectively. Compound 3 has lowest value of the potential ionization $(\mathrm{I}=$ $4.383 \mathrm{eV}$ ), so that will be the better electron donor. Compound 3 has the largest value of the affinity $(\mathrm{A}=2.020 \mathrm{eV})$, so it is the better electron acceptor. The chemical reactivity varies with the structural of molecules. Chemical hardness (softness) value of compound $3(\eta=1.181 \mathrm{eV}, \mathrm{S}=0.423 \mathrm{eV})$ is lesser (greater) among all the molecules. Thus, compound 4 is found to be more reactive than all the compounds. Compound 4 possesses higher electronegativity value $(\chi=3.872 \mathrm{eV})$ than all compounds so; it is the best electron acceptor. The value of $\omega$ for compound $3(\omega=4.339$ $\mathrm{eV}$ ) indicates that it is the stronger electrophiles than all compounds. Compound 3 has the smaller frontier orbital gap so, it is more polarizable and is associated with a high chemical reactivity, low kinetic stability and is also termed as soft molecule.

\subsection{Local reactivity descriptors}

The local reactivity has been analyzed by means of Fukui indices [27], an indication of the reactive centers within the molecules. These are measurement of the chemical reactivity, as well as an indicative of the reactive regions, nucleophilic and electrophilic behavior of the molecule [28]. The local (condensed) Fukui functions $\left(f_{\mathrm{k}} ; f_{\mathrm{k}} ; f_{\mathrm{k}}\right)$ are calculated using the procedure proposed by Yang and Mortier [29] based on a finite difference method are calculated at same calculation method B3LYP/6-31G (d,p) using

$$
\begin{aligned}
& \text { for nucleophilic attack } f_{k}^{+}=\left[q_{k}(N+1)-q_{k}(N)\right] \\
& \text { for electrophilic attack } f_{k}^{-}=\left[q_{k}(N)-q_{k}(N-1)\right] \\
& \text { for radical attack } f_{k}^{0}=\left[q_{k}(N+1)-q_{k}(N-1)\right] / 2
\end{aligned}
$$


Where $q(\mathrm{~N}), q(\mathrm{~N}+1)$, and $q(\mathrm{~N}-1)$ are the electronic population of the atom $\mathrm{k}$ in neutral, cationic and anionic systems respectively [30]. The reactive sites on (TTFs)- $N$-methylthiocarbamoyl 1-4 are calculated by the DFT/B3LYP method with 6-31G (d,p) basis set and shown in Tables 6-7.

Table 6 Order of the reactive sites on compounds 1 and 2

\begin{tabular}{llllllllll}
\hline \multicolumn{4}{c}{ Compound 1 } & \multicolumn{5}{c}{ Compound 2 } \\
\hline Atom & $4 \mathrm{C}$ & $1 \mathrm{C}$ & $12 \mathrm{C}$ & $2 \mathrm{C}$ & Atom & $4 \mathrm{C}$ & $1 \mathrm{C}$ & $2 \mathrm{C}$ & $3 \mathrm{C}$ \\
$\boldsymbol{f}^{+}$ & 0.091 & 0.065 & 0.052 & -0.026 & $\boldsymbol{f}^{+}$ & 0.087 & 0.083 & 0.053 & 0.052 \\
Atom & $11 \mathrm{C}$ & $15 \mathrm{C}$ & $9 \mathrm{C}$ & $10 \mathrm{C}$ & Atom & $12 \mathrm{C}$ & $16 \mathrm{C}$ & $6 \mathrm{C}$ & $25 \mathrm{C}$ \\
$\boldsymbol{f}^{-}$ & 0.193 & 0.108 & 0.069 & 0.036 & $\boldsymbol{f}^{-}$ & 0.192 & 0.081 & -0.005 & -0.027 \\
Atom & $4 \mathrm{C}$ & $2 \mathrm{C}$ & $3 \mathrm{C}$ & $1 \mathrm{C}$ & Atom & $12 \mathrm{C}$ & $16 \mathrm{C}$ & $6 \mathrm{C}$ & $25 \mathrm{C}$ \\
$\boldsymbol{f}^{\boldsymbol{o}}$ & -0.001 & -0.006 & -0.006 & -0.010 & $\boldsymbol{f}^{\boldsymbol{0}}$ & -0.044 & -0.093 & -0.027 & -0.034 \\
\hline
\end{tabular}

Table 7 Order of the reactive sites on compounds 3 and 4

\begin{tabular}{|c|c|c|c|c|c|c|c|c|c|}
\hline \multicolumn{5}{|c|}{ Compound 3} & \multicolumn{5}{|c|}{ Compound 4} \\
\hline Atom & $13 \mathrm{~N}$ & $15 \mathrm{~S}$ & $1 \mathrm{C}$ & $4 \mathrm{C}$ & Atom & $13 \mathrm{~N}$ & $4 \mathrm{C}$ & $1 \mathrm{C}$ & $2 \mathrm{C}$ \\
\hline$f^{+}$ & 0.148 & 0.125 & 0.100 & 0.063 & $f^{+}$ & 0.065 & 0.065 & 0.064 & 0.027 \\
\hline Atom & $12 \mathrm{C}$ & $16 \mathrm{C}$ & $6 \mathrm{C}$ & $26 \mathrm{C}$ & Atom & $12 \mathrm{C}$ & $16 \mathrm{C}$ & $6 \mathrm{C}$ & $25 \mathrm{C}$ \\
\hline$f$ & 0.163 & 0.052 & 0.019 & 0.000 & $f^{-}$ & 0.165 & 0.056 & 0.020 & -0.035 \\
\hline Atom & $12 \mathrm{C}$ & $2 \mathrm{C}$ & $3 \mathrm{C}$ & $6 \mathrm{C}$ & Atom & $2 \mathrm{C}$ & $3 \mathrm{C}$ & $4 \mathrm{C}$ & $1 \mathrm{C}$ \\
\hline$f^{o}$ & -0.007 & -0.011 & -0.011 & -0.012 & $f^{0}$ & -0.015 & -0.016 & -0.018 & -0.024 \\
\hline
\end{tabular}

From the tables 6-7, the parameters of local reactivity descriptors show that $4 \mathrm{C}$ and $13 \mathrm{~N}$ are the more reactive sites in compounds 1, 2, 3 and 4 respectively for nucleophilic attacks. The more reactive sites in radical attacks are 4C, 2C, forcompounds 1, 4 respectively and 12C for the both compounds $\mathbf{2}$ and $\mathbf{3}$. The more reactive sites for electrophilic attacks are $11 \mathrm{C}$ for compound $\mathbf{1}$ and $12 \mathrm{C}$ for compounds $2, \mathbf{3}$ and $\mathbf{4}$ respectively.

\subsection{Natural bond orbital analysis (NBO)}

Natural bond orbitals offers a handy basis for exploring charge transfer or conjugative interaction in molecular systems and is an efficient method for studying intra- and inter molecular bonding and interaction among bonds. In order to investigate the intra and intermolecular interactions, the stabilization energies of (TTFs)- $N$ methylthiocarbamoyl 1-4were performed by using second-order perturbation theory. For each donor NBO(i) and acceptor $\mathrm{NBO}(\mathrm{j})$, the stabilization energy $\mathrm{E}_{2}$ associated with electron delocalization between donor and acceptor is estimated as $[31,32]$.

$$
\mathrm{E}_{2}=\Delta E_{i j}=\mathrm{q}_{\mathrm{i}} \frac{F(\mathrm{i}, \mathrm{j})^{2}}{\varepsilon_{\mathrm{j}}-\varepsilon_{\mathrm{i}}}
$$

Where $\mathrm{q}_{\mathrm{i}}$ is the donor orbital occupancy, $\varepsilon_{\mathrm{i}}$ and $\varepsilon_{\mathrm{j}}$ are diagonal elements (orbital energies) and $F(\mathrm{i}$, j) is the off-diagonal NBO Fock matrix element [33].The results of second order perturbation theory analysis of the Fock Matrix at DFT/B3LYP method with 6-31G(d,p) basis set of theory of (TTFs)- $N$-methylthiocarbamoyl1-4 are presented in Tables 811. The intra molecular interaction for the title compounds is formed by the orbital overlap between: $\pi(\mathrm{C} 7-\mathrm{C} 8)$ and $\pi^{*}(\mathrm{C} 14-\mathrm{S} 17)$ for compound 1, $\pi(\mathrm{C} 5-\mathrm{C} 6)$ and $\pi^{*}(\mathrm{C} 11-\mathrm{S} 14)$ for compound $2, \pi(\mathrm{C} 5-\mathrm{C} 6)$ and $\pi^{*}(\mathrm{C} 12-\mathrm{S} 15)$ for compound 3 and $\pi(\mathrm{C} 5-\mathrm{C} 6)$ and $\pi^{*}(\mathrm{C} 12-\mathrm{S} 15)$ for compound 4 respectively, which result into intermolecular charge transfer (ICT) causing stabilization of the system. The intra molecular hyper conjugative interactions of $\pi(\mathrm{C} 7-\mathrm{C} 8)$ to $\pi^{*}(\mathrm{C} 14-\mathrm{S} 17)$ for compound $1, \pi(\mathrm{C} 5-\mathrm{C} 6)$ to $\pi^{*}(\mathrm{C} 11-\mathrm{S} 14)$ for compound $2, \pi(\mathrm{C} 5-\mathrm{C} 6)$ to $\pi^{*}(\mathrm{C} 12-\mathrm{S} 15)$ for compound 3 and $\pi(\mathrm{C} 5-\mathrm{C} 6)$ to

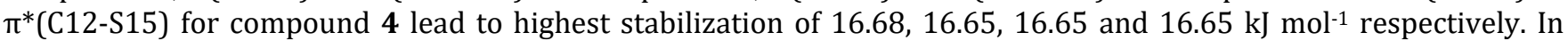
case of LP (1) N15 orbital to the $\pi^{*}(\mathrm{C} 14-\mathrm{S} 17)$ for compound 1, LP (1) N12 orbital to $\pi^{*}(\mathrm{C} 11-\mathrm{S} 14)$ for compound 2, LP (1) N13 orbital to $\pi^{*}(\mathrm{C} 12-\mathrm{S} 15)$ for compound 3, LP(1) N13 orbital to $\pi^{*}(\mathrm{C} 12-\mathrm{S} 15)$ for compound 4 respectively, show the stabilization energy of $79.96,79.33,79.98$ and $79.98 \mathrm{~kJ} \mathrm{~mol}^{-1}$ respectively. 
Table 8 Second order perturbation theory analysis of Fock matrix on NBO of compound 1

\begin{tabular}{|c|c|c|c|c|c|c|}
\hline Donor (i) & ED/e & Acceptor (j) & ED/e & $\begin{array}{l}\mathrm{E}(2) \\
\text { Kcal/mol }\end{array}$ & $\begin{array}{l}\mathrm{E}(\mathrm{j})-\mathrm{E}(\mathrm{i}) \\
\text { a.u }\end{array}$ & $\begin{array}{l}F(i . j) \\
\text { a.u }\end{array}$ \\
\hline LP(1) N15 & 1.64941 & $\pi^{*}(\mathrm{C} 14-\mathrm{S} 17)$ & 0.43843 & 79.96 & 0.21 & 0.117 \\
\hline LP(2) S13 & 1.74191 & $\pi^{*}(\mathrm{C} 7-\mathrm{C} 8)$ & 0.27820 & 24.81 & 0.25 & 0.071 \\
\hline LP(2) S11 & 1.77857 & $\pi^{*}(\mathrm{C} 2-\mathrm{C} 3)$ & 0.21737 & 22.68 & 0.25 & 0.068 \\
\hline LP(2) S10 & 1.78483 & $\pi^{*}(\mathrm{C} 2-\mathrm{C} 3)$ & 0.21737 & 22.14 & 0.26 & 0.067 \\
\hline LP(2) S12 & 1.78577 & $\pi^{*}(\mathrm{C} 7-\mathrm{C} 8)$ & 0.27820 & 22.12 & 0.24 & 0.066 \\
\hline $\mathrm{LP}(2) \mathrm{S} 12$ & 1.78577 & $\pi^{*}(\mathrm{C} 1-\mathrm{C} 6)$ & 0.41530 & 20.39 & 0.23 & 0.065 \\
\hline $\mathrm{LP}(2) \mathrm{S} 11$ & 1.77857 & $\pi^{*}(\mathrm{C} 1-\mathrm{C} 6)$ & 0.41530 & 20.11 & 0.24 & 0.065 \\
\hline LP(2) S10 & 1.78483 & $\pi^{*}(\mathrm{C} 1-\mathrm{C} 6)$ & 0.41530 & 19.87 & 0.24 & 0.065 \\
\hline LP(2) S13 & 1.74191 & $\pi^{*}(\mathrm{C} 1-\mathrm{C} 6)$ & 0.41530 & 19.24 & 0.25 & 0.064 \\
\hline$\pi(\mathrm{C} 7-\mathrm{C} 8)$ & 1.90244 & $\pi^{*}(\mathrm{C} 14-\mathrm{S} 17)$ & 0.43843 & 16.68 & 0.25 & 0.063 \\
\hline LP(2) S17 & 1.87081 & $\sigma^{*}(\mathrm{C} 14-\mathrm{N} 15)$ & 0.05492 & 11.85 & 0.67 & 0.081 \\
\hline$\pi(\mathrm{C} 14-\mathrm{S} 17)$ & 1.95875 & $\pi^{*}(\mathrm{C} 7-\mathrm{C} 8)$ & 0.27820 & 8.69 & 0.28 & 0.046 \\
\hline LP(2) S17 & 1.87081 & $\sigma^{*}(\mathrm{C} 8-\mathrm{C} 14)$ & 0.05054 & 6.97 & 0.63 & 0.060 \\
\hline$\sigma(\mathrm{C} 7-\mathrm{H} 9)$ & 1.97390 & $\sigma^{*}(\mathrm{C} 8-\mathrm{S} 12)$ & 0.02792 & 5.53 & 0.77 & 0.058 \\
\hline$\sigma(\mathrm{C} 2-\mathrm{H} 4)$ & 1.97510 & $\sigma^{*}(\mathrm{C} 3-\mathrm{S} 10)$ & 0.01922 & 5.47 & 0.76 & 0.058 \\
\hline$\sigma(\mathrm{C} 3-\mathrm{H} 5)$ & 1.97537 & $\sigma^{*}(\mathrm{C} 2-\mathrm{S} 11)$ & 0.01926 & 5.40 & 0.76 & 0.057 \\
\hline$\sigma(\mathrm{C} 1-\mathrm{S} 11)$ & 1.97236 & $\sigma^{*}(\mathrm{C} 6-\mathrm{S} 13)$ & 0.04304 & 5.26 & 0.81 & 0.058 \\
\hline$\sigma(\mathrm{C} 6-\mathrm{S} 12)$ & 1.97092 & $\sigma^{*}(\mathrm{C} 1-\mathrm{S} 10)$ & 0.04079 & 5.22 & 0.81 & 0.058 \\
\hline$\sigma(\mathrm{C} 6-\mathrm{S} 13)$ & 1.97296 & $\sigma^{*}(\mathrm{C} 1-\mathrm{S} 11)$ & 0.04063 & 5.08 & 0.82 & 0.058 \\
\hline$\sigma(\mathrm{C} 1-\mathrm{S} 10)$ & 1.97370 & $\sigma^{*}(\mathrm{C} 6-\mathrm{S} 12)$ & 0.05666 & 4.92 & 0.82 & 0.057 \\
\hline
\end{tabular}

Table 9 Second order perturbation theory analysis of Fock matrix on NBO of compound 2

\begin{tabular}{|c|c|c|c|c|c|c|}
\hline Donor(i) & ED/e & Acceptor(j) & ED/e & $\begin{array}{l}\text { E(2) } \\
\text { Kcal/mol }\end{array}$ & $\begin{array}{l}E(j)-E(i) \\
\text { a.u }\end{array}$ & $\begin{array}{l}F(i . j) \\
\text { a.u }\end{array}$ \\
\hline LP(1) N12 & 1.64607 & $\pi^{*}(\mathrm{C} 11-\mathrm{S} 14)$ & 0.45413 & 79.33 & 0.21 & 0.117 \\
\hline LP(2) S10 & 1.74543 & $\pi^{*}(\mathrm{C} 5-\mathrm{C} 6)$ & 0.28717 & 23.71 & 0.26 & 0.071 \\
\hline LP(2) S9 & 1.79158 & $\pi^{*}(\mathrm{C} 1-\mathrm{C} 4)$ & 0.41460 & 20.61 & 0.23 & 0.065 \\
\hline LP(2) S8 & 1.79310 & $\pi^{*}(\mathrm{C} 1-\mathrm{C} 4)$ & 0.41460 & 20.50 & 0.24 & 0.066 \\
\hline LP(2) S8 & 1.79310 & $\pi^{*}(\mathrm{C} 2-\mathrm{C} 3)$ & 0.23564 & 20.24 & 0.27 & 0.066 \\
\hline LP(2) S7 & 1.80005 & $\pi^{*}(\mathrm{C} 1-\mathrm{C} 4)$ & 0.41460 & 20.23 & 0.24 & 0.066 \\
\hline LP(2) S9 & 1.79158 & $\pi^{*}(\mathrm{C} 5-\mathrm{C} 6)$ & 0.28717 & 20.14 & 0.24 & 0.063 \\
\hline LP(2) S10 & 1.74543 & $\pi^{*}(\mathrm{C} 1-\mathrm{C} 4)$ & 0.41460 & 19.63 & 0.25 & 0.065 \\
\hline LP(2) S7 & 1.80005 & $\pi^{*}(\mathrm{C} 2-\mathrm{C} 3)$ & 0.23564 & 19.61 & 0.27 & 0.066 \\
\hline$\pi(\mathrm{C} 5-\mathrm{C} 6)$ & 1.87868 & $\pi^{*}(\mathrm{C} 11-\mathrm{S} 14)$ & 0.45413 & 17.94 & 0.24 & 0.064 \\
\hline LP(2) S14 & 1.86293 & $\sigma^{*}(\mathrm{C} 11-\mathrm{N} 12)$ & 0.05439 & 11.46 & 0.67 & 0.080 \\
\hline$\pi(\mathrm{C} 11-\mathrm{S} 14)$ & 1.96273 & $\pi^{*}(\mathrm{C} 5-\mathrm{C} 6)$ & 0.28717 & 8.17 & 0.28 & 0.046 \\
\hline LP(2) S14 & 1.86293 & $\sigma^{*}(\mathrm{C} 6-\mathrm{C} 11)$ & 0.04993 & 6.78 & 0.63 & 0.060 \\
\hline$\sigma(\mathrm{C} 6-\mathrm{C} 11)$ & 1.97480 & $\sigma^{*}(\mathrm{C} 5-\mathrm{C} 6)$ & 0.03246 & 5.55 & 1.30 & 0.076 \\
\hline$\sigma(\mathrm{C6} 6-\mathrm{S9})$ & 1.96953 & $\sigma^{*}(\mathrm{C} 5-\mathrm{C} 27)$ & 0.01875 & 5.36 & 1.00 & 0.066 \\
\hline$\sigma(\mathrm{C} 1-\mathrm{S} 8)$ & 1.97261 & $\sigma^{*}(\mathrm{C} 4-\mathrm{S} 10)$ & 0.04119 & 5.31 & 0.82 & 0.059 \\
\hline$\sigma(\mathrm{C} 4-\mathrm{S} 9)$ & 1.97090 & $\sigma^{*}(\mathrm{C} 1-\mathrm{S} 7)$ & 0.03789 & 5.26 & 0.81 & 0.059 \\
\hline$\sigma(\mathrm{C} 2-\mathrm{S} 8)$ & 1.97185 & $\sigma^{*}(\mathrm{C} 3-\mathrm{C} 23)$ & 0.01841 & 5.18 & 1.04 & 0.066 \\
\hline$\sigma(\mathrm{C} 3-\mathrm{C} 23)$ & 1.97864 & $\sigma^{*}(\mathrm{C} 2-\mathrm{C} 3)$ & 0.02980 & 5.17 & 1.29 & 0.073 \\
\hline$\sigma(\mathrm{C} 2-\mathrm{C} 19)$ & 1.97837 & $\sigma^{*}(\mathrm{C} 2-\mathrm{C} 3)$ & 0.02980 & 5.14 & 1.29 & 0.073 \\
\hline
\end{tabular}


Table 10 Second order perturbation theory analysis of Fock matrix on NBO of compound 3

\begin{tabular}{|c|c|c|c|c|c|c|}
\hline Donor(i) & ED/e & Acceptor (j) & ED/e & $\begin{array}{l}\mathrm{E}(2) \\
\text { Kcal/mol }\end{array}$ & $\begin{array}{l}E(j)-E(i) \\
\text { a.u }\end{array}$ & $\begin{array}{l}F(i . j) \\
\text { a.u }\end{array}$ \\
\hline LP(1) N13 & 1.64926 & $\pi^{*}(\mathrm{C} 12-\mathrm{S} 15)$ & 0.43796 & 79.98 & 0.21 & 0.117 \\
\hline$L P(2) S 11$ & 1.74157 & $\pi^{*}(\mathrm{C} 5-\mathrm{C} 6)$ & 0.27837 & 24.81 & 0.25 & 0.071 \\
\hline LP(2) S10 & 1.78440 & $\pi^{*}(\mathrm{C} 5-\mathrm{C} 6)$ & 0.27837 & 22.18 & 0.24 & 0.066 \\
\hline LP(2) S10 & 1.78440 & $\pi^{*}(\mathrm{C} 1-\mathrm{C} 4)$ & 0.41427 & 20.49 & 0.23 & 0.065 \\
\hline LP(2) S20 & 1.86829 & $\pi^{*}(\mathrm{C} 2-\mathrm{C} 3)$ & 0.37267 & 20.23 & 0.24 & 0.066 \\
\hline$L P(2) S 9$ & 1.79737 & $\pi^{*}(\mathrm{C} 1-\mathrm{C} 4)$ & 0.41427 & 20.14 & 0.24 & 0.065 \\
\hline$L P(2) S 9$ & 1.79737 & $\pi^{*}(\mathrm{C} 2-\mathrm{C} 3)$ & 0.37267 & 20.08 & 0.24 & 0.064 \\
\hline LP(2) S21 & 1.87001 & $\pi^{*}(\mathrm{C} 2-\mathrm{C} 3)$ & 0.37267 & 19.99 & 0.24 & 0.065 \\
\hline LP(2) S8 & 1.80323 & $\pi^{*}(\mathrm{C} 1-\mathrm{C} 4)$ & 0.41427 & 19.90 & 0.24 & 0.065 \\
\hline$L P(2) S 8$ & 1.80323 & $\pi^{*}(\mathrm{C} 2-\mathrm{C} 3)$ & 0.37267 & 19.57 & 0.24 & 0.064 \\
\hline LP(2) S11 & 1.74157 & $\pi^{*}(\mathrm{C} 1-\mathrm{C} 4)$ & 0.41427 & 19.26 & 0.25 & 0.064 \\
\hline$\pi(\mathrm{C} 5-\mathrm{C} 6)$ & 1.90266 & $\pi^{*}(\mathrm{C} 12-\mathrm{S} 15)$ & 0.43796 & 16.65 & 0.25 & 0.063 \\
\hline LP(2) S15 & 1.87027 & $\sigma^{*}(\mathrm{C} 12-\mathrm{N} 13)$ & 0.05498 & 11.88 & 0.67 & 0.081 \\
\hline$\pi(\mathrm{C} 12-\mathrm{S} 15)$ & 1.95866 & $\pi^{*}(\mathrm{C} 5-\mathrm{C} 6)$ & 0.27837 & 8.71 & 0.27 & 0.047 \\
\hline$L P(2) S 15$ & 1.87027 & $\sigma^{*}(\mathrm{C} 6-\mathrm{C} 12)$ & 0.05058 & 6.97 & 0.63 & 0.060 \\
\hline$\sigma(\mathrm{C} 2-\mathrm{S} 9)$ & 1.96919 & $\sigma^{*}(\mathrm{C} 3-\mathrm{S} 21)$ & 0.03093 & 5.91 & 0.83 & 0.062 \\
\hline$\sigma(\mathrm{C} 3-\mathrm{S} 8)$ & 1.96958 & $\sigma^{*}(\mathrm{C} 2-\mathrm{S} 20)$ & 0.03074 & 5.87 & 0.83 & 0.062 \\
\hline$\sigma(\mathrm{C} 5-\mathrm{H} 7)$ & 1.97380 & $\sigma^{*}(\mathrm{C} 6-\mathrm{S} 10)$ & 0.02794 & 5.55 & 0.77 & 0.058 \\
\hline$\sigma(\mathrm{C} 4-\mathrm{S} 10)$ & 1.97089 & $\sigma^{*}(\mathrm{C} 1-\mathrm{S} 8)$ & 0.03945 & 5.25 & 0.81 & 0.058 \\
\hline$\sigma(\mathrm{C} 1-\mathrm{S} 9)$ & 1.97051 & $\sigma^{*}(\mathrm{C} 4-\mathrm{S} 11)$ & 0.04315 & 5.20 & 0.82 & 0.058 \\
\hline
\end{tabular}

Table 11 Second order perturbation theory analysis of Fock matrix on NBO of compound 4

\begin{tabular}{|c|c|c|c|c|c|c|}
\hline Donor(i) & ED/e & Acceptor(j) & ED/e & $\begin{array}{l}\mathrm{E}(2) \\
\mathrm{Kcal} / \mathrm{mol}\end{array}$ & $\begin{array}{l}E(j)-E(i) \\
\text { a.u }\end{array}$ & $\begin{array}{l}F(i . j) \\
a . u\end{array}$ \\
\hline LP(1) N13 & 1.64926 & $\pi^{*}(\mathrm{C} 12-\mathrm{S} 15)$ & 0.43796 & 79.98 & 0.21 & 0.117 \\
\hline LP(2) S11 & 1.74157 & $\pi^{*}(\mathrm{C} 5-\mathrm{C} 6)$ & 0.27837 & 24.81 & 0.25 & 0.071 \\
\hline $\mathrm{LP}(2) \mathrm{S} 10$ & 1.78440 & $\pi^{*}(\mathrm{C} 5-\mathrm{C} 6)$ & 0.27837 & 22.18 & 0.24 & 0.066 \\
\hline $\mathrm{LP}(2) \mathrm{S} 10$ & 1.78440 & $\pi^{*}(\mathrm{C} 1-\mathrm{C} 4)$ & 0.41427 & 20.49 & 0.23 & 0.065 \\
\hline $\mathrm{LP}(2) \mathrm{S} 20$ & 1.86829 & $\pi^{*}(\mathrm{C} 2-\mathrm{C} 3)$ & 0.37267 & 20.23 & 0.24 & 0.066 \\
\hline LP(2) S9 & 1.79737 & $\pi^{*}(\mathrm{C} 1-\mathrm{C} 4)$ & 0.41427 & 20.14 & 0.24 & 0.065 \\
\hline LP(2) S9 & 1.79737 & $\pi^{*}(\mathrm{C} 2-\mathrm{C} 3)$ & 0.37267 & 20.08 & 0.24 & 0.064 \\
\hline LP(2) S21 & 1.87001 & $\pi^{*}(\mathrm{C} 2-\mathrm{C} 3)$ & 0.37267 & 19.99 & 0.24 & 0.065 \\
\hline LP(2) S8 & 1.80323 & $\pi^{*}(\mathrm{C} 1-\mathrm{C} 4)$ & 0.41427 & 19.90 & 0.24 & 0.065 \\
\hline$L P(2) S 8$ & 1.80323 & $\pi^{*}(\mathrm{C} 2-\mathrm{C} 3)$ & 0.37267 & 19.57 & 0.24 & 0.064 \\
\hline $\mathrm{LP}(2) \mathrm{S} 11$ & 1.74157 & $\pi^{*}(\mathrm{C} 1-\mathrm{C} 4)$ & 0.41427 & 19.26 & 0.25 & 0.064 \\
\hline$\pi(\mathrm{C} 5-\mathrm{C} 6)$ & 1.90266 & $\pi^{*}(\mathrm{C} 12-\mathrm{S} 15)$ & 0.43796 & 16.65 & 0.25 & 0.063 \\
\hline $\mathrm{LP}(2) \mathrm{S} 15$ & 1.87027 & $\sigma^{*}(\mathrm{C} 12-\mathrm{N} 13)$ & 0.05498 & 11.88 & 0.67 & 0.081 \\
\hline$\pi(\mathrm{C} 12-\mathrm{S} 15)$ & 1.95866 & $\pi^{*}(\mathrm{C} 5-\mathrm{C} 6)$ & 0.27837 & 8.71 & 0.27 & 0.047 \\
\hline $\mathrm{LP}(2) \mathrm{S} 15$ & 1.87027 & $\sigma^{*}(\mathrm{C} 6-\mathrm{C} 12)$ & 0.05058 & 6.97 & 0.63 & 0.060 \\
\hline$\sigma(\mathrm{C} 2-\mathrm{S} 9)$ & 1.96919 & $\sigma^{*}(\mathrm{C} 3-\mathrm{S} 21)$ & 0.03093 & 5.91 & 0.83 & 0.062 \\
\hline$\sigma(\mathrm{C} 3-\mathrm{S} 8)$ & 1.96958 & $\sigma^{*}(\mathrm{C} 2-\mathrm{S} 20)$ & 0.03074 & 5.87 & 0.83 & 0.062 \\
\hline$\sigma(\mathrm{C} 5-\mathrm{H} 7)$ & 1.97380 & $\sigma^{*}(\mathrm{C} 6-\mathrm{S} 10)$ & 0.02794 & 5.55 & 0.77 & 0.058 \\
\hline$\sigma(\mathrm{C} 4-\mathrm{S} 10)$ & 1.97089 & $\sigma^{*}(\mathrm{C} 1-\mathrm{S} 8)$ & 0.03945 & 5.25 & 0.81 & 0.058 \\
\hline$\sigma(\mathrm{C} 1-\mathrm{S} 9)$ & 1.97051 & $\sigma^{*}(\mathrm{C} 4-\mathrm{S} 11)$ & 0.04315 & 5.20 & 0.82 & 0.058 \\
\hline
\end{tabular}




\subsection{Nonlinear optical properties (NLO)}

The NLO activity provide the key functions for frequency shifting, optical modulation, optical switching and optical logic for the developing technologies in areas such as communication, signal processing and optical interconnections [34]. In the presence of an applied electric field, the energy of a system is a function of the electric field and the first hyperpolarizability is a third rank tensor that can be described by a $3 \times 3 \times 3$ matrix. The 27 components of the 3D matrix can be reduced to 10 components because of the Kleinman symmetry [35]. The matrix can be given in the lower tetrahedral format. It is obvious that the lower part of the $3 \times 3 \times 3$ matrices is a tetrahedral. The components of first hyperpolarizability $(\beta)$ are defined as the coefficients in the Taylor series expansion of the energy in the external electric field. When the external electric field is weak and homogeneous, this expansion is given below:

$$
E=E^{0}-\mu_{\alpha} F_{\alpha}-1 / 2 \alpha_{\alpha \beta} F_{\alpha} F_{\beta}-1 / 6 \beta_{\alpha \beta \gamma} F_{\alpha} F_{\beta} F_{\gamma}+\ldots
$$

Where $\mathrm{E}^{0}$ is the energy of the unperturbed molecules, $\mathrm{F}_{\alpha}$ is the field at the origin, $\mu_{\alpha}, \alpha_{\alpha \beta}$ and $\beta_{\alpha \beta \gamma}$ are the components of dipole moment, polarizability and first hyperpolarizability, respectively. The total static dipole moments $\mu$, the mean polarizabilities $\alpha_{0}$, the anisotropy of the polarizabilities $\Delta \alpha$ and the mean first hyperpolarizabilities $\beta$, using the $\mathrm{x}, \mathrm{y}$ and $\mathrm{z}$ components they are defined as [36, 37]:

Dipolemoment is $\mu=\left[\mu_{x}^{2}+\mu_{y}^{2}+\mu_{z}^{2}\right]^{1 / 2}$

Static polarizability is $\alpha_{0}=\left(\alpha_{x x}+\alpha_{y y}+\alpha_{z z}\right) / 3$

Total polarizability is $\Delta \alpha=2^{-1 / 2}\left[\left(\alpha_{x x}-\alpha_{y y}\right)^{2}+\left(\alpha_{y y}-\alpha_{z z}\right)^{2}+\left(\alpha_{z z}-\alpha_{x x}\right)^{2}+6 \alpha_{x z}^{2}\right]^{1 / 2}$

First order hyperpolarizability is $\beta=\left(\beta_{x}^{2}+\beta_{y}^{2}+\beta_{z}^{2}\right)^{1 / 2}$

Where

and

$$
\begin{aligned}
& \beta_{x}=\beta_{x x x}+\beta_{x y y}+\beta_{x z z} \\
& \beta_{y}=\beta_{y y y}+\beta_{x x y}+\beta_{y z z} \\
& \beta_{z}=\beta_{z z z}+\beta_{x x z}+\beta_{y y z}
\end{aligned}
$$

$$
\beta=\left[\left(\beta_{x x x}+\beta_{x y y}+\beta_{x z z}\right)^{2}+\left(\beta_{y y y}+\beta_{y z z}+\beta_{y x x}\right)^{2}+\left(\beta_{z z z}+\beta_{z x x}+\beta_{z y y}\right)^{2}\right]^{1 / 2}
$$

The polarizability $\left(\alpha_{0}\right)$ and the hyper polarizability $(\beta)$,the anisotropy of the polarizability $(\Delta \alpha)$ and the electric dipole moment $(\mu)$ of(TTFs)- $N$-methylthiocarbamoyl 1-4 are calculated by finite field method using B3LYP/6-31G (d,p) basis set and listed in Table 12.

Since the values of the polarizabilities $(\Delta \alpha)$ and the hyperpolarizabilities $(\beta)$ of the GAUSSIAN 09 output are obtained in atomic units (a.u.), the calculated values have been converted into electrostatic units (e.s.u.) (for $\alpha ; 1$ a.u $=0.1482 \mathrm{x}$ $10^{-24}$ e.s.u., for $\beta ; 1$ a.u $=8.6393 \times 10^{-33}$ e.s.u.). The calculated values of dipole moment $(\mu)$ for the title compounds were found to be $5.5574,4.6495,3.8982$ and $3.9329 \mathrm{D}$ respectively, which are approximately two times than to the value for urea ( $\mu=1.3732 \mathrm{D}$ ). Urea is one of the prototypical moleculesused in the study of the NLO properties of molecular systems. Therefore, it has been used frequently as a threshold value for comparative purposes. The calculated values of polarizability are $56.8207 \times 10^{-24}, 60.9411 \times 10^{-24}, 75.0280 \times 10^{-24}$ and $81.2628 \times 10^{-24}$ esu respectively; the values of anisotropy of the polarizability are 8.4208, 9.0315, 11.1191 and 12.0431 esu, respectively. The magnitude of the molecular hyperpolarizability $(\beta)$ is one of important key factors in a NLO system. The DFT/6-31G $(\mathrm{d}, \mathrm{p})$ calculated first hyperpolarizability value ( $\beta$ ) of (TTFs)- $N$-methylthiocarbamoyl molecules are equal to $120.8723 \times 10^{-33}, 86.6131$ $\times 10^{-33}, 269.4594 \times 10^{-33}$ and $109.2424 \times 10^{-33}$ esu. The first hyperpolarizability of title molecules is approximately $0.35,0.25,0.78$ and 0.32 times than those of urea ( $\beta$ of urea is $343.272 \times 10^{-33}$ esu obtained by B3LYP/6-311G $(\mathrm{d}, \mathrm{p})$ method). The above results show that (TTFs)- $N$-methylthiocarbamoyl 1-4 might have not the NLO applications. 
Table 12 Optical properties of (TTFs)- $N$-methylthiocarbamoyl 1-4

\begin{tabular}{|c|c|c|c|c|}
\hline Parameters & Compound 1 & Compound 2 & Compound 3 & Compound 4 \\
\hline$\beta_{X X X}$ & -71.3154 & -11.7927 & -204.5410 & -14.7824 \\
\hline$\beta_{y y y}$ & 12.7854 & 26.4285 & -8.8492 & 21.1703 \\
\hline$\beta_{z z z}$ & 10.1034 & 0.0064 & 0.9466 & 0.5930 \\
\hline$\beta_{x y y}$ & -3.4369 & 12.1164 & -7.4825 & 10.9020 \\
\hline$\beta_{x x y}$ & 44.2365 & 57.3176 & -67.3735 & 87.7507 \\
\hline$\beta_{x x z}$ & 73.6158 & 0.0698 & 16.8994 & 5.2223 \\
\hline$\beta_{x z z}$ & 17.6361 & -5.3135 & 3.0193 & -2.2249 \\
\hline$\beta_{y z z}$ & 5.3209 & 1.1606 & 16.8994 & -1.5333 \\
\hline$\beta_{y y z}$ & 7.6382 & 0.0074 & -6.5987 & -0.8788 \\
\hline$\beta_{x y z}$ & 4.9216 & -0.0014 & -24.0172 & -2.4201 \\
\hline$\beta(\mathrm{esu}) \times 10^{-33}$ & 120.8723 & 86.6131 & 269.4594 & 109.2424 \\
\hline$\mu_{x}$ & -0.8590 & -0.1774 & -2.5072 & -0.6921 \\
\hline$\mu_{y}$ & 4.2601 & 4.6461 & -2.9740 & 3.8708 \\
\hline$\mu_{z}$ & 3.4639 & 0.0029 & -0.2552 & 0.0765 \\
\hline$\mu(\mathrm{D})$ & 5.5574 & 4.6495 & 3.8982 & 3.9329 \\
\hline$\alpha_{x x}$ & -88.3324 & -92.2398 & -93.6463 & -94.9968 \\
\hline$\alpha_{y y}$ & -122.0861 & -135.9430 & -157.7701 & -159.1167 \\
\hline$\alpha_{z z}$ & -125.3905 & -141.0683 & -157.2980 & -159.8719 \\
\hline$\alpha_{x y}$ & 23.7331 & -22.7566 & 22.1576 & 28.5324 \\
\hline$\alpha_{x z}$ & 9.5652 & -0.0080 & 2.8137 & -0.3907 \\
\hline$\alpha_{y z}$ & -0.9257 & -0.0007 & -4.1133 & 0.4201 \\
\hline$\alpha_{0}(\mathrm{esu}) \times 10^{-24}$ & 56.8207 & 60.9411 & 75.0280 & 81.2628 \\
\hline$\Delta \alpha(\mathrm{esu}) \times 10^{-24}$ & 8.4208 & 9.0315 & 11.1191 & 12.0431 \\
\hline
\end{tabular}

\section{Conclusion}

With this research, we have successfully contributed to quantum computational calculations study of a (TTFs)-Nmethylthiocarbamoyl. The results of quantum chemical descriptors show that compound $\mathbf{3}$ has the smaller frontier orbital gap so, it is more polarizable and is associated with a high chemical reactivity, low kinetic stability and is also termed as soft molecule. The MEP map contour shows that the regions exhibiting the negative electrostatic potential are localized near TTF core and sulfur atom of $N$-methylthiocarbamoyl group while the regions presenting the positive potential are localized vicinity of the hydrogen atoms of alkyl and cycled groups. NBO analysis reveals that the important intramolecular charge transfer causing stabilization of the system to the title molecule and the intramolecular conjugative interaction lead to highest stabilization. NLO results show that (TTFs)- $N$ methylthiocarbamoyl have not nonlinear optical applications.

\section{Compliance with ethical standards}

\section{Acknowledgments}

This work was generously supported by the (General Directorate for Scientific Research and Technological Development, DGRS-DT) and Algerian Ministry of Scientific Research.

\section{Disclosure of conflict of interest}

The authors have declared that no conflict of interest exists among them. 


\section{References}

[1] Otsubo T, Aso Y and Takimiya K. (1996). Dimeric tetrathiafulvalenes: New electron donors. Advanced Materials, 8, 203-211.

[2] Adam M and Müllen K. (1994). Oligomeric tetrathiafulvalenes: extended donors for increasing the dimensionality of electrical conduction. Advanced Materials, 6, 439.

[3] Bryce MR, Davenport W, Goldenberg LM and Wang C. (1998). Macromolecular tetrathiafulvalene chemistry. Chemical Communications, 945-952.

[4] Shao X, Yamaji Y, Sugimoto T, Tanaka H, deCaro D and Valade L. (2009). Template-free growth of micro/nanocrystals of magnetic molecular conductor by electrocrystallization on platinum electrode. Chemistry of Materials, 21, 5569-5571.

[5] Martin N, Sánchez L, Herranz MÁ, Illescas B and Guldi DM. (2007). Electronic communication in tetrathiafulvalene $(\mathrm{ttf}) / \mathrm{c} 60$ systems: toward molecular solar energy conversion materials. Accounts of Chemical Research, 40, 1015-1024.

[6] Takano Y, Herranz MA, Martin N, Radhakrishnan SG, Guldi DM, Tsuchiya T, Nagase S and Akasaka T.(2010). Donor-acceptor conjugates of lanthanum endohedral metallofullerene and $\pi$-extended tetrathiafulvalene. Journal of the American Chemical Society, 132, 8048-8055.

[7] Wenger S, Bouit PA, Chen Q, Teuscher J,Censo DD, Humphry-Baker R,Moser JE, Delgado JL, Martin N, Zakeeruddin SM and Grätzel M. (2010). Efficient electron transfer and sensitizer regeneration in stable $\pi$ extended tetrathiafulvalene-sensitized solar cells. Journal of the American Chemical Society, 132, 5164-5169.

[8] Bryce MR. (1999). Tetrathiafulvalenes as $\pi$-electron donors for intramolecular charge-transfer materials. Advanced Materials, 11, 11-23.

[9] Meneses L, Araya A, Pilaquinga F, Contreras R and Fuentealba P. (2007). Local hardness: an application to electrophilic additions. Chemical Physics Letters, 446,170-175.

[10] Padmanabhan J, Parthasarathi R, Subramanian V and Chattaraj PK. (2007). Philicity based site activation model towards understanding the markovnikov regioselectivity rule. Journal of Molecular Structure: THEOCHEM, 804, $17-20$.

[11] Aizman A, Contreras R, Galvan M, Cedillo A, Santos JC and Chamorro E. (2002). The markovnikov regioselectivity rule in the light of site activation models. Journal of Physical Chemistry A, 106, 7844-7849.

[12] Suresh CH, Koga N and Gadre SR. (2001). Revisiting markovnikov addition to alkenes via molecular electrostatic potential. Journal of Organic Chemistry, 66, 6883-6890.

[13] Starodub VA and Starodub TN. (2014). Radical anion salts and charge transfer complexes based on tetracyanoquinodimethane and other strong $\pi$-electron acceptors. Russian Chemical Reviews, 83, 391-438.

[14] Frisch MJ, Trucks GW, Schlegel HB, Scuseria GE, Robb MA, Cheeseman JR, Scalmani G, Barone V, Mennucci B and Petersson GA. (2010). Gaussian 09, Revision C.01; Gaussian Inc.: Wallingford, CT, USA.

[15] Chidangil S, Shukla MK and Mishra PC. (1998). A molecular electrostatic potential mapping study of some fluoroquinolone anti-bacterial agents. Journal of Molecular Modeling, 4, 250-258.

[16] Luque FJ, Lopez JM and Orozco M. (2000). Perspective on electrostatic interactions of a solute with a continuum. A direct utilization of ab initio molecular potentials for the prevision of solvent effects". Theoretical Chemistry Accounts, 103,343-345.

[17] Fleming I. (1976). Frontier Orbital and Organic Chemical Reactions, Wiley, London.

[18] Subramanian N, Sundaraganesan N and Jayabharathi J. (2010). Molecular structure, spectroscopic (FT-IR, FTRaman, NMR, UV) studies and first-order molecular hyperpolarizabilities of 1, 2-bis (3-methoxy-4hydroxybenzylidene) hydrazine by density functional method. Spectrochimica Acta Part A: Molecular and Biomolecular, 76,259-269.

[19] Socrates G. (1980). Infrared characteristic group frequencies, Publications, Wiley Interscience.

[20] Varsanyi G. (1969). Vibrational spectra of benzene derivatives, academic press, New York.

[21] Parr RG and Yang W. (1989). Density functional theory of atoms and molecules, Oxford University Press, Oxford. 
[22] Ott JB and Goates JB. (2000). Calculations from statistical thermodynamics, Academic Press.

[23] Parr RG, Szentpaly LV and Liu SJ. (1999). Electrophilicity index. Journal of the American Chemical Society, 121, 1922-1929.

[24] Chattraj PK, Maiti B and Sarkar UJ. (2003). Philicity: a unified treatment of chemical reactivity and selectivity. Journal of Physical Chemistry A, 107, 4973-4981.

[25] Parr RG, Donnelly RA, Ley M and Palke WE. (1978). Electronegativity: the density functional viewpoint. Journal of the American Chemical Society, 68, 3807-3816.

[26] Parr RG and Pearson RG. (1983). Absolute hardness: companion parameter to absolute electronegativity. Journal of the American Chemical Society, 105, 7512-7516.

[27] Pearson RG. (1988). Absolute electronegativity and hardness: application to inorganic chemistry. Inorganic Chemistry, 27,734-740.

[28] Parr RG and Yang W. (1984). Density functional approach to the frontier-electron theory of chemical reactivity. Journal of the American Chemical Society, 106, 4049-4050.

[29] Yang W and Mortier WJ. (1986). The use of global and local molecular parameters for the analysis of the gasphase basicity of amines. Journal of the American Chemical Society, 108, 5708-5711.

[30] Khaled KF. (2010). Studies of iron corrosion inhibition using chemical, electro-chemical and computer simulation techniques. Electrochimica Acta, 55, 6523-6532.

[31] SchwenkeDW and TruhlarDG. (1985). Systematic study of basis set superposition errors in the calculated interaction energy of two hf molecules. Journal of Chemical Physics, 82, 2418-2426.

[32] Gutowski M and Chalasinski G. (1993). Accuracy of the boys and bernardi function counterpoise method. Journal of Chemical Physics, 98, 4728-4737.

[33] Prabakaran A and Muthu S. (2014). Normal coordinate analysis, molecular structure, vibrational and electronic spectral investigation of 7-(1, 3-dioxolan-2-ylmethyl)-1, 3-dimethylpurine-2,6-dione by ab initio HF and DFT method. Spectrochimica Acta Part A: Molecular and Biomolecular Spectroscopy, 118, 578-588.

[34] Geskin VM, Lambert C and Bredas JL. (2003). Origin of high second-and third-order nonlinear optical response in ammonio/borato diphenylpolyene zwitterions: the remarkable role of polarized aromatic groups. Journal of the American Chemical Society, 125, 15651-15658.

[35] Kleinman DA. (1977). Nonlinear dielectric polarization in optical media. Physical Review, 126, 1962-1979.

[36] Christiansen O, Gauss J and Stanton JF. (1999). Frequency-dependent polarizabilities and first hyperpolarizabilities of $\mathrm{CO}$ and $\mathrm{H} 2 \mathrm{O}$ from coupled cluster calculations. Journal of Physical Chemistry Letters, $305,147-155$

[37] Kleinman A. (1962). Nonlinear dielectric polarization in optical media. Physical Review, 126, 1977-1979.

\section{How to cite this article}

Tahar A, Amel B and Didier V. (2018). Quantum computational calculations of a series of tetrathiafulvalene derivatives linked to N-methylthiocarbamoyl group. GSC Biological and Pharmaceutical Sciences, 3(2), 11-23. 